\title{
Somatostatin Analogues according to Ki67 index in neuroendocrine tumours: an observational retrospective- prospective analysis from real life
}

\author{
Antongiulio Faggiano ${ }^{1}$, Anna Chiara Carratù ${ }^{2}$, Elia Guadagno ${ }^{3}$, Salvatore Tafuto ${ }^{4}$, \\ Fabiana Tatangelo5, Ferdinando Riccardi, ${ }^{5}$ Carmela Mocerino, Giovannella \\ Palmieri7, Vincenzo Damiano7, Roberta Siciliano ${ }^{8}$, Silvana Leo', Annamaria Mauro ${ }^{9}$, \\ Lucia Franca Tozzi $^{10}$, Claudia Battista ${ }^{11}$, Gaetano De Rosa ${ }^{3}$ and Annamaria Colao ${ }^{2}$ \\ ${ }^{1}$ Thyroid and Parathyroid Surgery Unit, Istituto Nazionale per lo Studio e la Cura dei Tumouri "Fondazione G. Pascale" IRCCS, \\ Napoli, Italy \\ 2 Endocrinology Unit, Department of Clinical Medicine and Surgery, Università di Napoli Federico II, Napoli, Italy \\ ${ }^{3}$ Pathology Unit, Department of Advanced Biomedical Sciences, Università di Napoli Federico II, Napoli, Italy \\ ${ }^{4}$ Medical Oncology Unit, Istituto Nazionale per lo studio e la cura dei tumouri "Fondazione G. Pascale" IRCCS, Napoli, Italy \\ ${ }^{5}$ Pathology Unit, Istituto Nazionale per lo Studio e la Cura dei Tumouri "Fondazione G. Pascale" IRCCS, Napoli, Italy \\ ${ }^{6}$ Oncology Unit, AORN Cardarelli, Napoli, Italy \\ 7 Oncology Unit, Department of Clinical Medicine and Surgery, Università di Napoli Federico II, Napoli, Italy \\ 8 Department of Industrial Engeenering, Università di Napoli Federico II, Napoli, Italy \\ 9 Oncology Unit, Ospedale Civico, Lecce, Italy \\ ${ }^{10}$ Oncology Unit, IRCCS Casa Sollievo della Sofferenza, San Giovanni Rotondo, Italy \\ ${ }^{11}$ Endocrinology Unit, IRCCS Casa Sollievo della Sofferenza, San Giovanni Rotondo, Italy \\ Correspondence to: Antongiulio Faggiano, email: afaggian@unina.it
}

Keywords: neuroendocrine tumours, Ki67 index, octreotide, lanreotide, somatostatin analogues

Received: August 04, $2015 \quad$ Accepted: December 10, $2015 \quad$ Published: December 19, 2015

\section{ABSTRACT}

Somatostatin analogues (SSAs) have shown limited and variable antiproliferative effects in neuroendocrine tumours (NETS). Whether tumour control by SSAs depends on grading based on the 2010 WHO NET classification is still unclear. The aim of this study is to evaluate the efficacy of long-acting SSAs in NETs according to Ki67 index.

An observational Italian multicentre study was designed to collect data in patients with gastro-entero-pancreatic or thoracic NETs under SSA treatment. Both retrospective and prospective data were included and they were analysed in line with Ki67 index, immunohistochemically evaluated in tumour samples and graded according to WHO classification (G1 = Ki67 index 0-2\%, G2 = Ki67 index 3-20\%, G3 = Ki67 index $>20 \%$ ).

Among 601 patients with NET, 140 with a histologically confirmed gastroentero-pancreatic or thoracic NET or NET with unknown primary were treated with lanreotide autogel or octreotide LAR. An objective tumour response was observed in $11 \%$, stability in $58 \%$ and progression in $31 \%$. Objective response and tumour stability were not significantly different between G1 and G2 NETs. Progression free survival was longer but not significantly different in G1 than G2 NETs (median: 89 vs 43 months, $p=0.15$ ). The median PFS was significantly longer in NETs showing Ki67 $<5 \%$ than in those showing Ki67 $\geq 5 \%$ ( 89 vs 35 months, $p=0.005$ ).

SSA therapy shows significant antiproliferative effects in well differentiated low/ intermediate-proliferating NETs, not only G1 but also in G2 type. A Ki67 index of 5\% seems to work better than $3 \%$ to select the best candidates for SSA therapy. 


\section{INTRODUCTION}

Somatostatin analogues (SSAs) represent a consolidated therapeutic approach in patients with neuroendocrine tumour (NET). Octreotide and lanreotide have initially been shown effective in controlling endocrine syndromes associated with NETs [1, 2]. Subsequently, their role as antiproliferative agents has clearly been demonstrated in randomized trials conducted in patients with well differentiated NETs $[3,4]$. Modern NET guidelines report that SSAs are currently a therapeutic option in patients with NETs, whatever the site of primary tumour, stage, or activity [5, 6, 7]. Moreover, SSAs are started early in the therapeutic algorithm, both for their efficacy in arresting tumour proliferation and for their manageability and excellent patients' tolerance.

SSAs are more frequently shown to induce tumour stabilization (about $50-80 \%$ of patients with progressive well differentiated NETs) than objective responses ( < $10 \%)[3,4,8,9]$. Recently, two randomized trials have been conducted in patients with NETs to evaluate the efficacy of long-acting slow-release SSA formulations and showed a significant antiproliferative effect $[3,4]$. The PROMID study (double-blind placebo-controlled prospective randomized study), first demonstrated that octreotide LAR significantly prolonged the time to progression in a population of metastatic welldifferentiated low-proliferating NETs of small intestine [3]. However, $95 \%$ of patients had tumours with Ki67 less than $2 \%$. Subsequently, the CLARINET study (double-blind controlled study of Lanreotide anti-proliferative response in NET) performed in patients with non functioning well-/ moderately differentiated GEP NETs (70\% G1, 30\% G2 with Ki67 ranging 3-10\%) and including 45\% pNETs, confirmed a significant improvement of progression free survival (PFS) in patients treated with lanreotide Autogel as compared to those receiving placebo [4].

These studies have changed the indication of SSA in NET therapy even if some concerns still require attention. In particular, it is unclear whether SSAs are effective in all type of well-/moderately differentiated NETs, regardless from Ki67 index.

Thus the aim of the current study was at analyzing the anti-tumour effects of long-acting lanreotide and octreotide in patients with NET according to Ki67 index.

\section{RESULTS}

\section{PFS}

The median PFS of 106 G1-G2 NET patients receiving SSA therapy was 89 months (CI interval, 58.9-119 months). PFS was higher but not significantly different in G1 than G2 NETs (median: 89 vs. 43 months, $p=0.15)$ (Figure 1). A Ki67 index of 5\% was the best cutoff at the ROC analysis to separate patients according to tumour progression, with a sensitivity and specificity of 65 and $69 \%$, respectively $(p=0.004)$. When this Ki67 cut-off was considered, PFS was significantly higher in NETs with Ki67 $<5 \%$ than in those with Ki67 $\geq 5 \%$ (median: 89 vs. 35 months, $p=0.005$ )(Figure 2). PFS was not different between GEP and thoracic NET (median: 89 vs. 59 months, $p=0.531$ ), while was higher in GEP and thoracic NETs than in those with unknown primary tumour (median: 89 vs. 35 months, $p=0.048$ ), in loco-regional than metastatic disease (median: 89 vs. 40 months, $p=$ 0.005 ) and in . Within the GEP group, the median PFS was 62 months for pancreatic and 102 months for ileal NETs, without significant differences $(p=0.464)$. Within the thoracic group, the median PFS was 59 months for lung and 42 months for thymic NETs, without significant differences $(p=0.077)$. There was no difference between functioning and non-functioning tumours (median: $59 \mathrm{vs.}$ 89 months, $p=0.710$ ), as well as between sporadic and MEN1 (median: 59 vs. 89 months, $p=0.533$ ) and between Octreoscan $/{ }^{68} \mathrm{Ga}$-PET positive and negative (median: 89 months vs. median not reached, $p=0.965$ ). At the Cox regression analysis, both ki67 index $\geq 5 \%(\operatorname{Exp}(\mathrm{B}): 2.011$, IC95\%: 0.959-4.216) and distant metastases (Exp(B): 1.483, IC95\%: 0.990-2.220) were independent negative prognostic factors.

\section{Tumour response}

An objective tumour response was observed in 11\% of cases. Tumour stability occurred in $58 \%$, while tumour progression in $31 \%$ (Table 4). Objective response and tumour stability were not significantly different between G1 and G2 NETs, as well as between loco-regional disease and distant metastases (Table 4). Clinical benefit (including objective response and tumour stability) was not significantly different between G1 and G2 NETs, as well as between the group of patients with Ki67 index $\geq 5 \%$ and the one with Ki67 index $<5 \%$. On the contrary, the clinical benefit was significantly higher in patients with loco-regional disease than in those with distant metastases $(p=0.002)$, as well as in patients with GEP NETs than others $(p=0.02)$. Tumour stage was not significantly different between the group of subjects with Ki67 index $\geq 5 \%$ and the one with Ki67 index $<5 \%$.

Among the 14 patients who experienced a switch from standard to high dose SSA treatment, an objective response occurred in 2 patients $(14.3 \%)$, while tumour progression in 2 others $(14.3 \%)$. Stable disease was observed in the remaining 10 (71.4\%). In 4 of 5 patients with clinical syndrome uncontrolled by standard dose of SSAs, a control of the syndrome was achieved on high dose regimen. 
Table 1: Patients' characteristics: 140 patients with G1-G2-G3 NET treated with somatostatin analogues

\begin{tabular}{|c|c|c|}
\hline Parameters & & $\mathrm{n}^{\circ}$ of patients (\%) \\
\hline Age & mean \pm SE, range & $59 \pm 2.6(21-86)$ \\
\hline Gender M/F & & $74 / 66$ \\
\hline \multirow[t]{7}{*}{ Site of primary tumour } & Lung & $26(19)$ \\
\hline & Thymus & $5(4)$ \\
\hline & Stomach & $8(6)$ \\
\hline & Pancreas & $60(44)$ \\
\hline & Ileum & $18(12)$ \\
\hline & Other sites* & $7(3)$ \\
\hline & Unknown primary & $16(12)$ \\
\hline \multirow[t]{2}{*}{ Biology } & Sporadic & $123(88)$ \\
\hline & MEN1 & $17(12)$ \\
\hline \multirow[t]{3}{*}{ Grading } & G1 & $49(35)$ \\
\hline & G2 & $61(44)$ \\
\hline & G3 & $30(21)$ \\
\hline \multirow[t]{2}{*}{ Stage } & Loco-regional disease & $62(45)$ \\
\hline & Distant metastases & $78(55)$ \\
\hline Nonfunctioning tumour & & $119(85)$ \\
\hline \multirow[t]{3}{*}{ Functioning tumour } & Zollinger-Ellison syndrome & $6(4.3)$ \\
\hline & Hypoglicemic syndrome & $5(3.6)$ \\
\hline & Carcinoid syndrome & $10(7.1)$ \\
\hline \multirow[t]{4}{*}{ Positive circulating NE markers } & Serum Chromogranin-A & $66(47)$ \\
\hline & Serum Gastrin & $11(7.8)$ \\
\hline & Serum Insulin/C-peptide & $5(3.6)$ \\
\hline & 24-h-urinary 5-HIAA & $10(7.1)$ \\
\hline \multirow[t]{2}{*}{ Octreoscan } & Positive & $46(75)$ \\
\hline & Negative & $15(25)$ \\
\hline \multirow[t]{2}{*}{${ }^{68}$ Ga-DOTATATE -PET } & Positive & $29(83)$ \\
\hline & Negative & $6(17)$ \\
\hline
\end{tabular}

NET: neuroendocrine tumour; NE: neuroendocrine; 5-HIAA: 5-hydroxyindolacetic acid; *colon-rectum, duodenum, appendix.

\section{DISCUSSION}

NETs are well recognized to specifically express somatostatin receptors and to bind SSAs. Their antiproliferative effects on pancreatic and ileal NET cells were first demonstrated in vitro $[12,13,14]$. Since nineties, clinical studies reported SSAs to exert some antitumour efficacy in different types of NET. However, these data were based on not-randomized studies performed on small, heterogeneous and retrospective series of patients $[8,9,15-18]$. Published in 2009, the PROMID study has been a milestone in the therapy of NETs, because it was the first randomized prospective phase 3 trial investigating SSA therapy in NETs [3]. It was possible to demonstrate that SSAs are an effective and manageable therapeutic approach in well differentiated low-proliferating NETs of small intestine. The most relevant consequence was that SSAs were included in NET guidelines as a valid therapeutic option in patients with metastatic or inoperable well differentiated NETs [5-7]. The CLARINET study, an international randomized multicenter phase III trial, further enlarges the spectrum of NET types to consider candidates for SSA therapy [4]. In CLARINET, not only small intestine, but also pancreatic and hindgut NETs were included, showing a $53 \%$ risk reduction to tumour progression or death with lanreotide versus placebo. Besides, if PROMID was performed before the 2010 WHO classification of NETs and only included lowproliferating tumours with Ki67 $<2 \%$, CLARINET was addressed not only to G1 but also to G2 with Ki67 $<10 \%$, demonstrating that SSAs are effective in both.

If these two pivotal studies have promoted SSAs as one of the main systemic therapies of NETs, on the other hand some questions remain unsolved. In particular, it is not clear if all well differentiated NETs, regardless from Ki67 index, are responsive to SSAs. In this meaning, G2 with Ki67 between 10 and 20\% and even those G3 with well differentiated histology and Ki67 $<50 \%$ could be potential candidates for SSA therapy. The current study aims to evaluate SSA therapy in NETs of different origin and grading and to establish the impact of Ki67 index in 
Table 2: Patients' characteristics: 106 patients with G1-G2 NET treated with somatostatin analogues

\begin{tabular}{|c|c|c|c|}
\hline Parameters & & $\begin{array}{l}\text { G1 } \\
n^{\circ}(\%)\end{array}$ & $\begin{array}{l}\text { G2 } \\
n^{\circ}(\%)\end{array}$ \\
\hline Total number & & $49(46)$ & $57(54)$ \\
\hline Age & mean \pm SE, range & $56+16$ & $60+12$ \\
\hline Gender M / F & & $27 / 22$ & $27 / 30$ \\
\hline \multirow[t]{7}{*}{ Site of primary tumour } & Lung & $6(12)$ & $7(12)$ \\
\hline & Thymus & $1(2.0)$ & $4(7.0)$ \\
\hline & Stomach & $3(6.1)$ & $5(8.8)$ \\
\hline & Pancreas & $29(59)$ & $20(35)$ \\
\hline & Ileum & $5(10)$ & $10(17)$ \\
\hline & Other sites* & $1(2.0)$ & $6(10)$ \\
\hline & Unknown primary & $4(8.2)$ & $5(8.8)$ \\
\hline \multirow[t]{2}{*}{ Biology } & Sporadic & $36(73)$ & $53(93)$ \\
\hline & MEN1 & $13(27)$ & $4(7.0)$ \\
\hline \multirow[t]{2}{*}{ Stage } & Loco-regional disease & $24(49)$ & $27(47)$ \\
\hline & Distant metastases & $25(51)$ & $30(53)$ \\
\hline Nonfunctioning tumour & & $40(79)$ & $49(88)$ \\
\hline \multirow[t]{3}{*}{ Functioning tumour } & Zollinger-Ellison syndrome & $2(4.1)$ & $3(6)$ \\
\hline & \begin{tabular}{|l|} 
Hypoglicemic syndrome \\
\end{tabular} & $3(6)$ & $1(2)$ \\
\hline & Carcinoid syndrome & $4(11)$ & $4(4)$ \\
\hline \multirow[t]{4}{*}{ Positive circulating NE markers } & Serum Chromogranin-A & $27(55)$ & $34(60)$ \\
\hline & Serum Gastrin & $10(20)$ & $11(19)$ \\
\hline & Serum Insulin & $2(4.1)$ & $2(3.5)$ \\
\hline & 24-h-urinary 5-HIAA & $4(8.2)$ & $3(5.3)$ \\
\hline \multirow[t]{2}{*}{ Octreoscan } & Positive & $20(80 \%)$ & $19(76 \%)$ \\
\hline & Negative & $5(20 \%)$ & $6(24 \%)$ \\
\hline \multirow[t]{2}{*}{${ }^{68}$ Ga-DOTATATE -PET } & Positive & $14(93 \%)$ & $14(93 \%)$ \\
\hline & Negative & $1(7 \%)$ & $1(7 \%)$ \\
\hline
\end{tabular}

NET: neuroendocrine tumour; NE: neuroendocrine; 5-HIAA: 5-hydroxyindolacetic acid; *colon-rectum, duodenum, appendix

Table 3: Somatostatin analogue schedule treatment in 106 patients with G1-G2 NET

\begin{tabular}{|l|l|l|}
\hline \multicolumn{2}{|l|}{ Schedule } & Number of Patient \\
\hline Initial treatment & LAN $120 \mathrm{mg} / 28 \mathrm{~d}$ & 35 \\
\hline & LAR $30 \mathrm{mg} / 28 \mathrm{~d}$ & 71 \\
\hline First treatment switch & LAN from $120 \mathrm{mg} / 28 \mathrm{~d}$ to LAN $120 \mathrm{mg} / 21 \mathrm{~d}$ & 2 \\
\hline & LAR from $30 \mathrm{mg} / 28 \mathrm{~d}$ to LAR $30 \mathrm{mg} / 21 \mathrm{~d}$ & 6 \\
\hline & LAR from $30 \mathrm{mg} / 28 \mathrm{~d}$ to LAN $120 \mathrm{mg} / 28 \mathrm{~d}$ & 2 \\
\hline & LAR from $30 \mathrm{mg} / 28 \mathrm{~d}$ to LAN $120 \mathrm{mg} / 21 \mathrm{~d}$ & 2 \\
\hline & LAR from $30 \mathrm{mg} / 28 \mathrm{~d}$ to LAN $90 \mathrm{mg} / 21 \mathrm{~d}$ & 2 \\
\hline Second treatment switch & LAN from $120 \mathrm{mg} / 28 \mathrm{~d}$ to LAN $120 \mathrm{mg} / 21 \mathrm{~d}$ & 2 \\
\hline & LAN from $120 \mathrm{mg} / 21 \mathrm{~d}$ to LAN $120 \mathrm{mg} / 14 \mathrm{~d}$ & 4 \\
\hline & LAN from $90 \mathrm{mg} / 21 \mathrm{~d}$ to LAN $120 \mathrm{mg} / 21 \mathrm{~d}$ & 2 \\
\hline & LAR from $30 \mathrm{mg} / 21 \mathrm{~d}$ to LAR 30 mg/14 d & 2 \\
\hline Final treatment & LAN $120 \mathrm{mg} / 28 \mathrm{~d}$ & 33 \\
\hline & LAN $120 \mathrm{mg} / 21 \mathrm{~d}$ & 4 \\
\hline & LAN $120 \mathrm{mg} / 14 \mathrm{~d}$ & 4 \\
\hline & LAR $30 \mathrm{mg} / 28 \mathrm{~d}$ & 59 \\
\hline & LAR $30 \mathrm{mg} / 21 \mathrm{~d}$ & 4 \\
\hline & LAR $30 \mathrm{mg} / 14 \mathrm{~d}$ & 2 \\
\hline
\end{tabular}




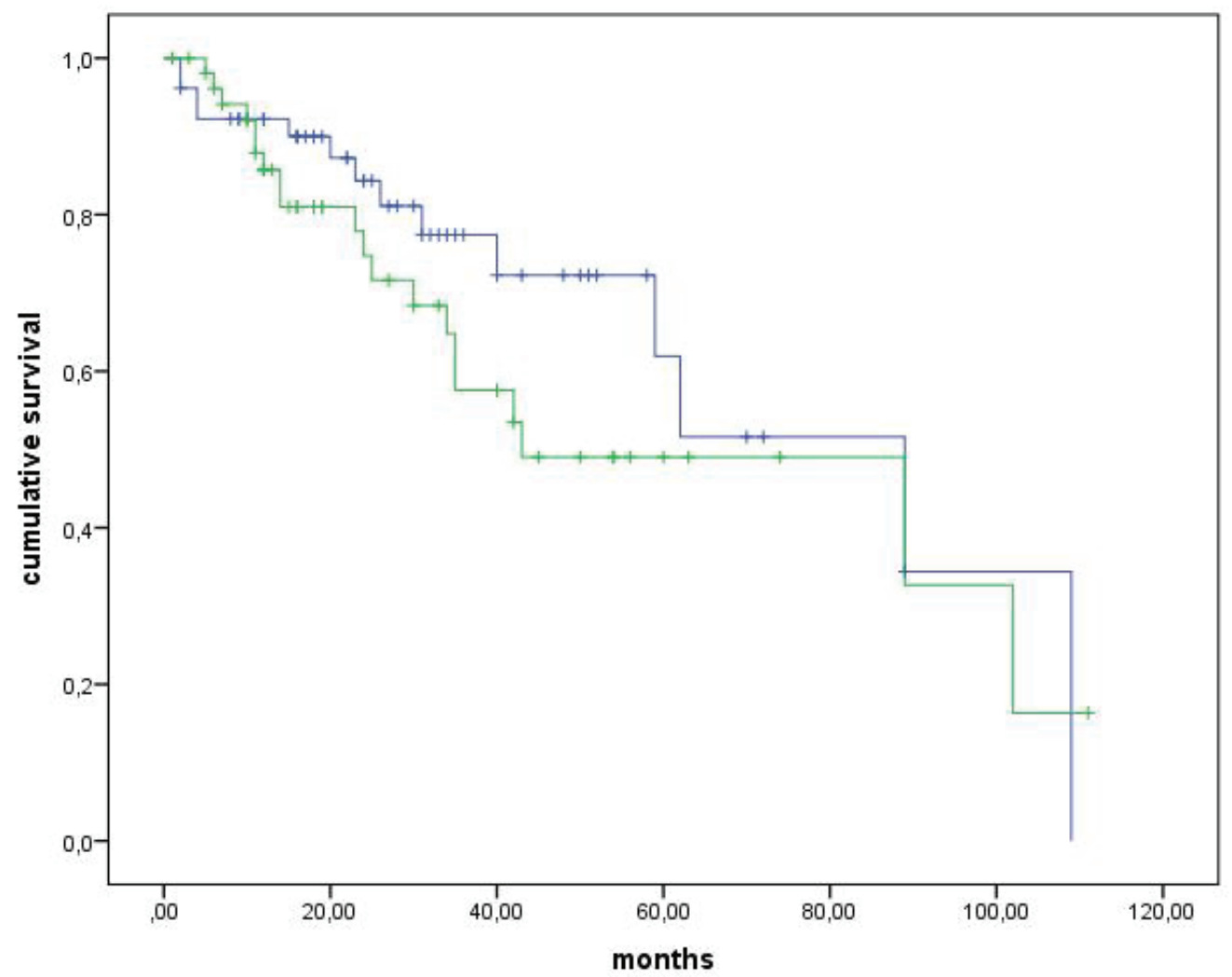

Figure 1: Log-rank analysis. These Kaplan-Meier survival curves show progression free survival for patients with grading G1 and G2.

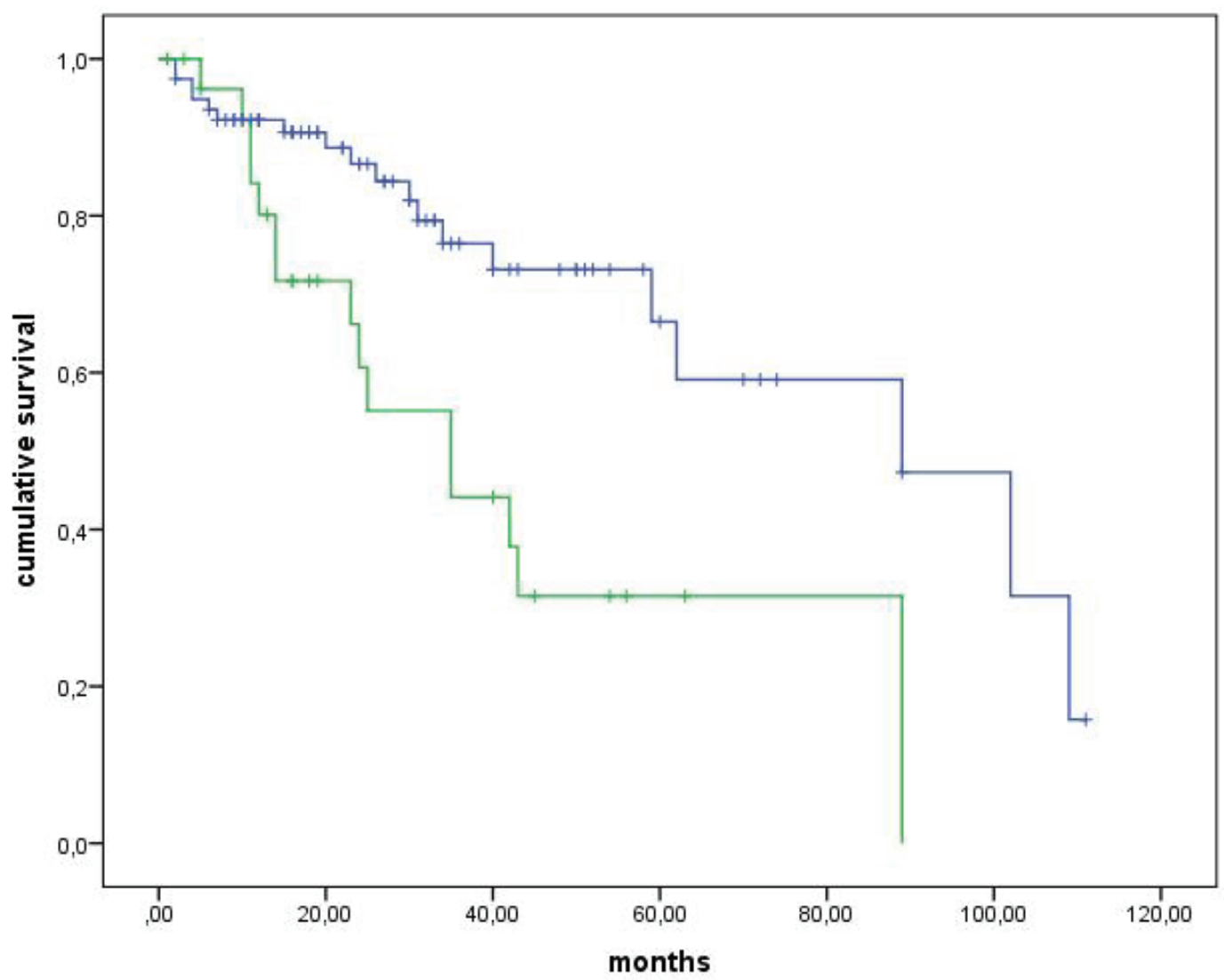

Figure 2: Log-rank analysis. These Kaplan-Meier survival curves show progression free survival for patients with Ki67 $<5 \%$ and $\geq 5 \%$. 
Table 4: Rate of tumour response to treatment with somatostatin analogues in 106 pts with G1-G2 NET

\begin{tabular}{|c|c|}
\hline & Tumour Response \\
\hline Total patients & $\mathrm{n}^{\circ}(\%)$ \\
\hline Complete Response & $2(2.0)$ \\
\hline Partial Response & $10(9.0)$ \\
\hline Stable Disease & $61(58)$ \\
\hline Progression & $33(31)$ \\
\hline \multicolumn{2}{|l|}{ G1 NET } \\
\hline Complete Response & $1(2.0)$ \\
\hline Partial Response & $3(6.0)$ \\
\hline Stable Disease & $33(67)$ \\
\hline Progression & $12(25)$ \\
\hline \multicolumn{2}{|l|}{ G2 NET } \\
\hline Complete Response & $1(2.0)$ \\
\hline Partial Response & $7(12)$ \\
\hline Stable Disease & $28(49)$ \\
\hline Progression & $21(37)$ \\
\hline \multicolumn{2}{|c|}{ Patients with Lung - Thymus NET } \\
\hline Complete Response & 0 \\
\hline Partial Response & $1(6.0)$ \\
\hline Stable Disease & $11(61)$ \\
\hline Progression & $6(33)$ \\
\hline \multicolumn{2}{|c|}{ Patients with Pancreas NET } \\
\hline Complete Response & 0 \\
\hline Partial Response & $6(12)$ \\
\hline Stable Disease & $30(61)$ \\
\hline Progression & $13(27)$ \\
\hline \multicolumn{2}{|c|}{ Patients with Gastro-Intestinal NET } \\
\hline Complete Response & $2(7.0)$ \\
\hline Partial Response & $2(7.0)$ \\
\hline Stable Disease & $16(53)$ \\
\hline Progression & $10(33)$ \\
\hline \multicolumn{2}{|c|}{ Patients with unknown primary NET } \\
\hline Complete Response & 0 \\
\hline Partial Response & $1(11)$ \\
\hline Stable Disease & $4(44)$ \\
\hline Progression & $4(44)$ \\
\hline \multicolumn{2}{|c|}{ Patients with loco-regional disease } \\
\hline Complete Response & $1(2.0)$ \\
\hline Partial Response & $5(10)$ \\
\hline Stable Disease & $37(72)$ \\
\hline Progression & $8(16)$ \\
\hline \multicolumn{2}{|c|}{ Patients with distant metastases } \\
\hline Complete Response & $1(1.8)$ \\
\hline Partial Response & $5(9.2)$ \\
\hline Stable Disease & $24(44)$ \\
\hline Progression & $25(45)$ \\
\hline
\end{tabular}

NET: neuroendocrine tumour

the response to SSA. Although the observational mainly retrospective study design represents a limitation of the study, some relevant results have been obtained. The most relevant finding was that PFS was not significantly different between G1 and G2, while it was significantly different according to Ki67 more or less than 5\%. Median 
PFS was 89 months in NETs with Ki67 $<5 \%$ and 35 months in those with $\mathrm{Ki} 67 \geq 5 \%$. This finding highlights a completely different clinical behaviour between these subgroups. It also explains why there is no difference in responsiveness to SSAs between G1 and G2 tumours which are separated by a Ki67 cut-off of 3\%. At the opposite, a cut-off of 5\% seems to well distinguish two subpopulations of well differentiated NETs, those with low proliferation rate and indolent clinical course and those with moderately high proliferation rate and tendency to progression. A previous study performed on 21 nonfunctioning pNETs highlighted that a Ki67 index $<$ $5 \%$ correlated with tumour stability under treatment with octreotide LAR [19]. Again a Ki67 index of up to 5\%, together with pretreatment stability and hepatic tumour load of up to $25 \%$, were correlated with tumour stability under treatment with lanreotide [20]. A similar finding has been also reported in two prognostic studies performed in lung NETs, $[21,22]$ where a Ki67 cut-off of 4\% was able to separate patients with significantly different disease free and overall survival.

Beyond these results, it is not negligible that SSAs are an effective therapeutic instrument also in well differentiated NETs with moderately high proliferation rate. In the current study, clinical benefit of SSAs was observed in $63 \%$ of G2 NETs, although objective response rate was really scarce and progression rate quite relevant in this subgroup. Even in G3 NETs is possible to hypothesize some efficacy of SSAs. Recently, a French study found a rate of $43 \%$ of well differentiated NETs in the G3 subgroup [23]. There was a significant difference between well and poorly differentiated G3 NETs in terms of octreoscan uptake ( 88 vs 50\%) and median overall survival (41 vs 17 months). All responders to cisplatin chemotherapy were poorly differentiated G3 NETs. Of consequence, the well differentiated G3 NETs could constitute a NET subgroup different from other G3. SSAs could be effective in this subgroup as in G1-G2. In the current study, 30 patients of the 140 who were initially selected as SSA population belonged to the subgroup G3. All of them were excluded from this analysis because of concomitant systemic therapies. To avoid confounding results this subgroup will be analyzed in a separate study.

Interestingly, Ki67 index and tumour stage resulted to be both independent negative prognostic factors of progression at the multivariate analysis, suggesting that NET patients with $\mathrm{Ki} 67<5 \%$ are expected to be the best responders to SSAs regardless from any other factor. This finding from a large series of NET patients is a helpful element to define the identikit of the best candidate to SSA therapy, following the initial indications pointed out by the PROMID and CLARINET studies [3, 4].

Another point of interest in NET therapy with SSA concerns the use of high dose schedules in place of standard dose [24]. To shorten the interval of administration of octreotide LAR from $30 \mathrm{mg}$ every 28 days to $30 \mathrm{mg}$ every 21 days was proven to slow tumour progression in patients with GEP and thoracic well differentiated NETs [25]. Previously, very high dose octreotide and lanreotide treatment resulted in high rate of tumour stabilization in patients with progressive well differentiated GEP NETs [26, 27]. In one study, where lanreotide was used in subcutaneous formulation at the dose of $15 \mathrm{mg}$ a day, one complete and one partial objective response were also observed [26]. The current study was not focused on this aspect. However, in 14 of 106 patients there was a switch from standard to high dose SSA treatment, following tumour progression in 9 and uncontrolled clinical syndrome in 5. An objective response was observed in $14.3 \%$, while stable disease in $71.4 \%$ of cases. Control of clinical syndrome was achieved in $80 \%$ of those patients who were still symptomatic under standard doses of SSAs.

In conclusion, SSA therapy shows significant antiproliferative effects in well differentiated low/ intermediate-proliferating NETs, not only G1 but also in G2 type. A Ki67 index $\leq 5 \%$ seems to indicate the best candidates for SSA therapy. Further prospective studies need to be performed on this topic as well as on the role of SSA in G2 with Ki67 > 10\% and in well differentiated G3 NETs, on the role of SSA high dose in NET therapy.

\section{PATIENTS AND METHODS}

\section{Study design}

This is an observational Italian multicentre study designed to collect data on patients with gastro-enteropancreatic and thoracic NETs or NETs with unknown primary origin who were receiving treatment with SSA. The observational data have been collected through an e-CRF and stored in a centralized computer database ad hoc created. Both retrospective data of patients in treatment with SSA from 2005 and prospective data of patients treated with SSA from March 2012 to April 2014 were included. Objective response rate (ORR) and progression free survival were evaluated according to Ki67 index, evaluated by counting the percentage of nuclei positive to the Mib-1 primary antibody upon 2000 tumour cells.

Between January 2005 and April 2014, 601 patients diagnosed with NET in the five centres involved in the study were examined as potentially eligible for the study. Inclusion criteria were: a) a histologically documented diagnosis of NET, revised according to the last WHO classification criteria for NET of gastro-entero-pancreatic, bronchial and thymic origin $[10,11]$ b) Ki67 index immunohistochemically evaluated in representative tumour samples to grade tumours according to WHO classification of NETs (G1 = Ki67 index 0-2\%, G2 = Ki67 
index 3-20\%, G3 = Ki67 index $>20 \%$ ), c) treatment with SSAs at standard doses for at least 3 months (octreotide LAR $30 \mathrm{mg} / 28 \mathrm{~d}$, lanreotide autogel $120 \mathrm{mg} / 28 \mathrm{~d}$ ). In each center involved in the study, the pathological diagnosis was revised by at least two pathologists dedicated to NET and participating to the multidisciplinary tumour board for NET.

Exclusion criteria were: a) histology not revised according to the last WHO classifications, b) Ki67 index unavailable, c) treatment with SSAs for $<3$ months. The study was conducted in accordance with the Declaration of Helsinki and approved by the Federico II University Ethics Committee (protocol n²27/2011 approved on 11/01/12). All patients gave written informed consent.

\section{Patient characteristics}

Data of 140 patients fulfilling the inclusion criteria have been reported in the current study. Mean age was $59 \pm 2.6$ yrs. Male:female ratio was 1.1 (Table 1). Onehundred twenty-three patients had a sporadic NET $(88 \%)$ and 17 a MEN1-related NET (12\%). The most frequent site was pancreas accounting for $44 \%$ of cases, followed by lung (19\%) and ileum (12\%) (Table 1). Tumour grading was $\mathrm{G} 1$ in $35 \%, \mathrm{G} 2$ in $44 \%$, G3 in $21 \%$. Tumour stage included NETs without metastases in $26 \%$, locoregional metastases in $29 \%$, distant metastases in $45 \%$. Primary tumour had been surgically removed in $66 \%$ of patients. NET was non-functioning in $85 \%$ of cases. Functioning NET accounted for $15 \%$ of cases, including ZollingerEllison syndrome (ZES) in 4.3\%, hypoglycemic hyperinsulinemic syndrome in $3.6 \%$, carcinoid syndrome in $7.1 \%$. Abnormally increased neuroendocrine markers were serum chromogranin-A (CGA) in $47 \%$ patients, gastrin in $7.8 \%$, insulin/C-peptide in 3.6\% and/or 24-hour urinary 5-hydroxyindolacetic acid (5-HIAA) in $7.1 \%$ (Table 1).

A somatostatin receptor scintigraphy was performed in 61 patients, by using intravenous injection of Indium111-DTPA-Phe1-octreotide (Octreoscan, Mallinckrodt Medical, Petten, The Netherlands; 120-200 MBq) with SPECT/CT fusion images. Octreoscan was positive in 46 cases $(75 \%)$. A ${ }^{68} \mathrm{Ga}$-DOTATATE PET was performed in 35 patients, by administering $120-220 \mathrm{MBq}$ of activity, with acquisition of images 45-60 min post-injection. There was a positive ${ }^{68} \mathrm{Ga}$-PET uptake in 29 cases $(83 \%)$.

In 34 of the 140 cases $(24 \%)$, including 30 with G3 (100\% of this subgroup) and 4 with G2 NET (6\% of this subgroup), other systemic anti-tumour therapies were started concomitantly or within 3 months from the beginning of SSA therapy. In particular, other therapies concomitant to SSA were chemotherapy in 27 cases and targeted therapy in 7 cases. To limit confounding data, we excluded from final analysis all patients with G3 and 4 patients with G2 NET treated with therapies other than SSAs. Finally 106 patients, entering all the inclusion criteria and resulting to be affected with G1 (49 patients) and G2 NET (57 patients), according to Ki67 index, form the basis for the statistical analysis (Table 2). Both in G1 and G2 NETs, pancreas was the main primary site followed by ileum and lung. Sporadic NETs accounted for the most of cases while MEN1 NETs were about one fourth of G1 tumours and a minority of G2. Tumour stage was equally balanced between G1 and G2. NET was functioning in $79 \%$ of $\mathrm{G} 1$ and $88 \%$ of G2, respectively. The most frequent syndrome was carcinoid syndrome in G1 and ZES in G2. Abnormally increased serum CGA occurred in $55 \%$ of $\mathrm{G} 1$ and $60 \%$ of G2. Octreoscan and ${ }^{68} \mathrm{Ga}$-DOTATATE PET uptake was similar in G1 and G2 (Table 2).

\section{Treatment with SSA}

Initial SSA treatment included octreotide LAR 30 $\mathrm{mg} / 28 \mathrm{~d}$ in 71 patients and lanreotide autogel $120 \mathrm{mg} / 28$ $\mathrm{d}$ in 35 patients. The median treatment duration with SSA was 23 months (range, 3-88 months). The initial SSA dose subsequently changed in 14 patients, because of tumour progression in 9 and uncontrolled clinical syndrome in 5. Octreotide was switched to lanreotide in 6 cases (Table 3). At the final follow-up under SSA treatment, 65 patients received octreotide LAR and 41 patients received lanreotide autogel.

\section{Efficacy and safety assessment}

Efficacy was evaluated in terms of progression free survival (PFS) and tumour response according to the RECIST definitions for tumour [19]. The radiologic assessment of tumour lesions was performed by contrast enhanced computerized tomography (CT) or magnetic resonance imaging (MRI), at baseline and every 3-6 months during the follow-up period. Endoscopy and endoscopic ultrasonography (EUS) were also performed in combination with $\mathrm{CT} / \mathrm{MRI}$ where appropriate. In patients experiencing increase of SSA dose after initial tumour progression, PFS was evaluated at the last SSA dose.

\section{Statistical analysis}

The statistical analysis was performed with the SPSS package (Cary, NC, USA). Data were expressed as mean \pm SEM. The significance was set at 5\%. Comparisons of tumour responses among different groups of patients were performed with the Chi-square test with Yates correction or Fisher exact test. PFS was calculated using the Kaplan-Meier method and comparison between subgroups was performed by using the log-rank test. Cox regression analysis was performed to compare variables which were significant at the univariate test. The Ki67 
index was analyzed by receiver operator characteristic (ROC) analysis by using a non parametric model to determine the best cutoff to distinguish patients who are in progression from those who are not in progression.

\section{ACKNOWLEDGMENTS}

All the participants to the ELIOS (Educational Learning Investigational Observational Study) Multicentre Study. All authors approved the final version of the manuscript including the authorship list.

\section{CONFLICTS OF INTEREST}

Antongiulio Faggiano: Novartis, Ipsen (RF); Salvatore Tafuto: Novartis, Ipsen, Italfarmaco (RF); Ferdinando Riccardi: Novartis, Ipsen (RF); Giovannella Palmieri: Novartis, Ipsen (RF); Silvana Leo: Ipsen (RF); Lucia Franca Tozzi: Ipsen (RF); Annamaria Colao: Novartis, Ipsen (RF)(C)(BM).

The other authors indicated no financial relationship.

(E) Employment; (C) Consultancies; (RF) Research funding to the Department; (H) Honoraria; (O) Ownership of stock or shares; (R) Royalties; (P) Patents; (BM) Board membership.

\section{GRANT SUPPORT}

This work was partially supported by an unrestricted grant from Ipsen, as well as by a grant from the Italian Minister of the University and Research in Rome (no. 2011 RBAP11884M).

\section{REFERENCES}

1. Oberg K, Kvols L, Caplin M, Delle Fave G, de Herder W, Rindi G, Ruszniewski P, Woltering EA, Wiedenmann B. Consensus report on the use of somatostatin analogs for the management of neuroendocrine tumours of the gastroenteropancreatic system. Ann Oncol 2004; 15: 96673.

2. Tomassetti P, Migliori M, Gullo L. Slow-release lanreotide treatment in endocrine gastrointestinal tumours. Am J Gastroenterol 1998; 93: 1468-71.

3. Rinke A, Müller HH, Schade-Brittinger C, Klose KJ, Barth P, Wied M, Mayer C, Aminossadati B, Pape UF, Bläker M, Harder J, Arnold C, Gress T, Arnold R; PROMID Study Group. Placebo-controlled, double-blind, prospective, randomized study on the effect of octreotide LAR in the control of tumour growth in patients with metastatic neuroendocrine midgut tumours: a report from the PROMID Study Group. J Clin Oncol 2009; 27: 4656-63.

4. Caplin ME, Pavel M, Ćwikła JB, Phan AT, Raderer M, Sedláčková E, Cadiot G, Wolin EM, Capdevila J, Wall L, et al. CLARINET Investigators. Lanreotide in metastatic enteropancreatic neuroendocrine tumours. N Engl J Med 2014; 371: 224-33.

5. Oberg K, Akerström G, Rindi G, Jelic S. ESMO Guidelines Working Group Neuroendocrine gastroenteropancreatic tumours: ESMO Clinical Practice Guidelines for diagnosis, treatment and follow-up . Ann Oncol 2010; 21Suppl 5: v223-7.

6. Pavel M, Baudin E, Couvelard A, Krenning E, Öberg K, Steinmüller T, Anlauf M, Wiedenmann B, Salazar R. Barcelona Consensus Conference participants. ENETS Consensus Guidelines for the management of patients with liver and other distant metastases from neuroendocrine neoplasms of foregut, midgut, hindgut, and unknown primary. Neuroendocrinology 2012; 95: 157-76.

7. Kulke MH, Shah MH, Benson AB 3rd, Bergsland E, Berlin JD, Blaszkowsky LS, Emerson L, Engstrom PF, Fanta P, Giordano T, Goldner WS, Halfdanarson TR, Heslin MJ, et al. Neuroendocrine tumours, version 1.2015. J Natl Compr Canc Netw 2015; 13: 78-108.

8. Arnold R, Benning R, Neuhaus C, Rolwage M, Trautmann ME. Gastroenteropancreatic endocrine tumours: effect of Sandostatin on tumour growth. The German Sandostatin Study Group. Digestion 1993; 54Suppl 1: 72-5.

9. Wymenga AN, Eriksson B, Salmela PI, Jacobsen MB, Van Cutsem EJ, Fiasse RH, Välimäki MJ, Renstrup J, de Vries EG, Oberg KE. Efficacy and safety of prolonged-release lanreotide in patients with gastrointestinal neuroendocrine tumours and hormone-related symptoms. J Clin Oncol 1999; 17: 1111.

10. Rindi G, Arnold R, Capella C, Klimstra DS, Klöppel G, Komminoth P \& Solcia E. Nomenclature and classification of digestive neuroendocrine tumours. In World Health Organization Classification of Tumours, Pathology and Genetics of Tumours of the Digestive System 2010; pp 10-12. Eds F Bosman \& F Carneiro. Lyon: IARC Press.

11. Travis WD, Brambilla E, Muller-Hermelink HK, Harris CC. Pathology \& Genetics: Tumours of the Lung, Pleura, Thymus and Heart, WHO International Histological Classification of Tumours. Lyon: IARC Press. 2004

12. Reubi JC, Schaer JC, Waser B, Mengod G. Expression and localization of somatostatin receptor SSTR1, SSTR2, and SSTR3 messenger RNAs in primary human tumours using in situ hybridization. Cancer Res 1994; 54: 3455-9.

13. de Herder WW, Hofland LJ, van der Lely AJ, Lamberts SW. Somatostatin receptors in gastroentero-pancreatic neuroendocrine tumours. Endocr Relat Cancer 2003; 10: 451-8.

14. Papotti M, Bongiovanni M, Volante M, Allìa E, Landolfi S, Helboe L, Schindler M, Cole SL, Bussolati G. Expression of somatostatin receptor types 1-5 in 81 cases of gastrointestinal and pancreatic endocrine tumours. A correlative immunohistochemical and reverse-transcriptase polymerase chain reaction analysis. Virchows Arch 2002; 440: 461-75. 
15. Saltz L, Trochanowski B, Buckley M, Heffernan B, Niedzwiecki D, Tao Y, Kelsen D. Octreotide as an antineoplastic agent in the treatment of functional and nonfunctional neuroendocrine tumours. Cancer 1993; 72: 244 8.

16. di Bartolomeo M, Bajetta E, Buzzoni R, Mariani L, Carnaghi C, Somma L, Zilembo N, di Leo A. Clinical efficacy of octreotide in the treatment of metastatic neuroendocrine tumours. A study by the Italian Trials in Medical Oncology Group. Cancer 1996; 77: 402-8.

17. Arnold R, Trautmann ME, Creutzfeldt W, Benning R, Benning M, Neuhaus C, Jürgensen R, Stein K, Schäfer H, Bruns C, Dennler HJ. Somatostatin analogue octreotide and inhibition of tumour growth in metastatic endocrine gastroenteropancreatic tumours. Gut 1996; 38: 430-8.

18. Ruszniewski P, Ish-Shalom S, Wymenga M, O'Toole D, Arnold R, Tomassetti P, Bax N, Caplin M, Eriksson B, Glaser B, Ducreux M, Lombard-Bohas C, de Herder WW et al. Rapid and sustained relief from the symptoms of carcinoid syndrome: results from an open 6-month study of the 28-day prolonged-release formulation of lanreotide. Neuroendocrinology 2004; 80: 244-51.

19. Butturini G, Bettini R, Missiaglia E, Mantovani W, Dalai I, Capelli P, Ferdeghini M, Pederzoli P, Scarpa A, Falconi M. Predictive factors of efficacy of the somatostatin analogue octreotide as first line therapy for advanced pancreatic endocrine carcinoma. Endocr Relat Cancer 2006; 13: 1213 21.

20. Palazzo M, Lombard-Bohas C, Cadiot G, MatysiakBudnik T, Rebours V, Vullierme MP, Couvelard A, Hentic O, Ruszniewski P. Ki67 proliferation index, hepatic tumour load, and pretreatment tumour growth predict the antitumoural efficacy of lanreotide in patients with malignant digestive neuroendocrine tumours. Eur J Gastroenterol Hepatol 2013; 25: 232-8.

21. Grimaldi F, Muser D, Beltrami CA, Machin P, Morelli A, Pizzolitto S, Talmassons G, Marciello F, Colao AA, Monaco R, Monaco G, Faggiano A. Partitioning of bronchopulmonary carcinoids in two different prognostic categories by ki-67 index. Front Endocrinol 2011; 19: 2-20.

22. Rindi G, Klersy C, Inzani F, Fellegara G, Ampollini L, Ardizzoni A, Campanini N, Carbognani P, De Pas TM, Galetta D, Granone PL, Righi L, Rusca M, et al. Grading the neuroendocrine tumours of the lung: an evidence-based proposal. Endocr Relat Cancer 2013; 21: 1-16.

23. Vélayoudom-Céphise FL, Duvillard P, Foucan L, Hadoux J, Chougnet CN, Leboulleux S, Malka D, Guigay J, Goere D, Debaere T, Caramella C, Schlumberger M, Planchard D, et al. Are G3 ENETS neuroendocrine neoplasms heterogeneous? Endocr Relat Cancer 2013; 20: 649-57.

24. Broder MS, Beenhouwer D, Strosberg JR, Neary MP, Cherepanov D. Gastrointestinal neuroendocrine tumours treated with high dose octreotide-LAR: A systematic literature review. World J Gastroenterol 2015; 21: 1945-55.

25. Ferolla P, Faggiano A, Grimaldi F, Ferone D, Scarpelli
G, Ramundo V, Severino R, Bellucci MC, Camera LM, Lombardi G, Angeletti G, Colao A.. Shortened interval of long-acting octreotide administration is effective in patients with well-differentiated neuroendocrine carcinomas in progression on standard doses. J Endocrinol Invest 2012; 35: 326-31.

26. Faiss S, Räth U, Mansmann U, Caird D, Clemens N, Riecken EO, Wiedenmann B. Ultra-high-dose lanreotide treatment in patients with metastatic neuroendocrine gastroenteropancreatic tumours. Digestion 1999; 60: 46976.

27. Welin SV, Janson ET, Sundin A, Stridsberg M, Lavenius E, Granberg D, Skogseid B, Oberg KE, Eriksson BK. Highdose treatment with a long-acting somatostatin analogue in patients with advanced midgut carcinoid tumours. Eur J Endocrinol 2004; 151: 107-12. 